Check for updates

Cite this: RSC Adv., 2019, 9, 16479

\title{
Growing prospects of DNA nanomaterials in novel biomedical applications
}

\author{
Zhiguang Suo, $\uparrow^{a}$ Jingqi Chen, $\dagger^{a}$ Xialing Hou, ${ }^{a}$ Ziheng $\mathrm{Hu}^{a}{ }^{a}$ Feifei Xing ${ }^{\mathrm{b}}$ \\ and Lingyan Feng $\mathbb{D}^{* a}$
}

As an important genetic material for life, DNA has been investigated widely in recent years, especially in interdisciplinary fields crossing nanomaterials and biomedical applications. It plays an important role because of its extraordinary molecular recognition capability and novel conformational polymorphism. DNA is also a powerful and versatile building block for the fabrication of nanostructures and nanodevices. Such DNA-based nanomaterials have also been successfully applied in various aspects ranging from biosensors to biomedicine and special logic gates, as well as in emerging molecular nanomachines. In this present mini-review, we briefly overview the recent progress in these fields. Furthermore, some challenges are also discussed in the conclusions and perspectives section, which aims to stimulate broader scientific interest in DNA nanotechnology and its biomedical applications.

Received 19th February 2019 Accepted 7th May 2019

DOI: 10.1039/c9ra01261c

rsc.li/rsc-advances

\section{DNA biosensors}

\section{Introduction}

Deoxyribonucleic acid (DNA) is a biological molecule that consists of various base pairs for storage and propagation of genetic information. At the same time, DNA has also become a powerful and versatile functional material in nanotechnology and in biomedical applications, which benefit from its exciting physicochemical properties. Apart from the classic righthanded B-form double helix DNA, ${ }^{1}$ other DNA structures, such as the A-/Z-form and triplex, G-quadruplex and i-motif DNA etc., were developed later and have been widely applied. ${ }^{2}$ In addition, the more complicated conformational polymorphism DNA structures (e.g. DNA origami) have also been used and assembled in DNA nanotechnology. These functional nanostructures can be considered as templates or scaffolds for biomedical applications with novel functions. ${ }^{3}$ Furthermore, a great deal of DNA based biocomputing applications have been developed, which cannot be ignored within the rapid growth of DNA nanotechnology.

In this mini-review, we mainly focus on the role of DNA in biosensors, disease diagnostics and in therapeutic applications. Furthermore, we summarize the strategies of DNA nanostructures applied in logic gates and biocomputing, as well as in molecular nanomachines. We hope that this review will provide useful information towards broader scientific interests in DNA nano-biomedical/biocomputing applications.

\footnotetext{
${ }^{a}$ Materials Genome Institute, Shanghai University, Shanghai 200444, China. E-mail: lingyanfeng@t.shu.edu.cn

${ }^{b}$ Department of Chemistry, College of Science, Shanghai University, Shanghai 200444, China

$\dagger$ These authors contributed equally.
}

Biosensors are a class of analytical devices that have biological sensing elements, which convert a biological response into an analytically useful signal via a physicochemical transducer. DNA biosensors have been widely applied in biological fields, environment monitoring and in the food safety industry. DNA plays an important role in the design and application of a biosensor, including as a target, ${ }^{4}$ a recognition motif, ${ }^{5}$ a staple strand for linking ${ }^{6,7}$ and as a signal report probe etc. ${ }^{8,9}$ DNAbased biosensors have gained significant achievements over the past decades. ${ }^{10}$ In this section, electrochemical and fluorescent DNA biosensors will be first introduced according to their signal readout, and recent publications of DNA-based biosensors will be mainly summarized, particularly with respect to heavy metal ions, cancer biomedicine, and pathogen detections.

A typical electrochemical DNA-based (E-DNA) sensing platform generally involves a redox-labelled single strand DNA (ssDNA) probe immobilized on an electrode surface. ${ }^{11}$ Then the target-binding event will induce a change in the DNA structure, ${ }^{12}$ which has been proven to be rapid, sensitive, and reagentless..$^{13}$ Aptamer, as a new kind of selected DNA/RNA, has been widely employed to construct electrochemical/optical sensors with a highly specific binding ability. ${ }^{14}$ In addition, some novel nanomaterials, such as CdSe quantum dots, are labelled on the DNA signal strand as probes to realize signal amplification. ${ }^{15}$ To enhance the performance of electrochemical DNA sensors, Plaxco's group has systematically investigated the influence of different electrode surface modifications for favourable performances. ${ }^{16,17}$ By adopting two labelled probes (e.g. methylene blue, $\mathrm{MB}$, and anthraquinone, $\mathrm{AQ}$ ) with 
distinguishable electroactive potentials, a dual-reporter approach greatly eliminates E-AB baseline drift, even in flowing, undiluted whole blood (Fig. 1A). ${ }^{18} \mathrm{MB}$, AQ and ferrocene (Fc) are widely used electroactive probes in E-DNA sensors with stable redox signal readouts. Fan et al. developed a series of works using the tetrahedral structure of DNA to construct EDNA biosensors. In such DNA nanostructures, rigid branched DNA motifs could be obtained through complementary base pairing, and then further assembled into discrete finite objects. In order to investigate the DNA-mediated charge transport (CT) method, they modified the redox probes at different positions on the 3D tetrahedral DNA. CT rate measurements provided unambiguous evidence that the intercalative MB undergoes efficient mediated CT over longer distances along the duplex, whereas the non-intercalative $\mathrm{Fc}$ probe tunnels electrons through the space. Furthermore, ultrasensitive microRNA detection has also been realized by combining the tetrahedral DNA nanostructure and hybridization chain reaction amplification (Fig. 1B). ${ }^{19}$

Another typical DNA self-assembled nanostructure, DNA origami, has also been successfully applied in biosensing, smart drug delivery, enzyme cascades and in analysis platforms, etc. Very recently, Hemmig et al. explored the potential applications of DNA origami nanotechnology in novel optical voltage sensing nanodevices. The voltage responsive DNA origami structures were labelled with a single pair of fluorescent dyes and were

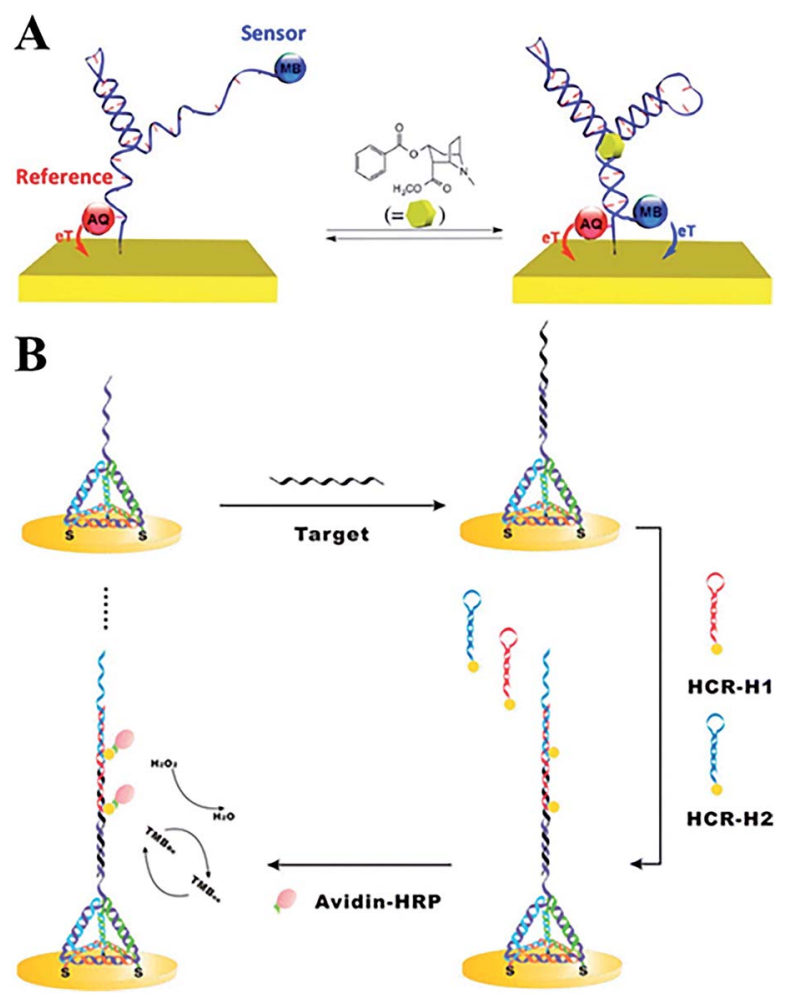

Fig. 1 (A) Electrochemical aptamer-based sensors with dual-reporter drift correction. (B) 3D tetrahedral DNA scaffold and hybridization chain reaction for electrochemical miRNA detection. These figures have been adapted from ref. 18 and 19, with permission from the American Chemical Society. immobilized on a nanocapillary tip. Upon application of an electric field, controlled structural changes could be obtained. This novel proof-of-concept sensing mechanism opens up a new pathway for determining the mechanical properties of DNA origami, enabling potential application in voltage sensors. ${ }^{20} 3 \mathrm{D}$ origami structures are stable enough to resist deformation in harsh environments, making them suitable for potential application in in vivo biosensing.

Fluorescence detection demonstrates an immediate response and real time detection with high sensitivity and minimal sample consumption properties. Natural state DNA is usually non-fluorescent, so fluorescent DNA biosensors always employ an external fluorophore. ${ }^{21}$ With the application of a labelled probe, various fluorescent DNA biosensors have been constructed. Carboxyfluorescein (FAM) and other fluorescent dyes are commonly used to functionalize DNA and are quenched by the complementary strand labelled with a quenching group..$^{22-24}$

In addition, a very common and effective approach is to introduce novel nanomaterials (gold and silver nanoclusters, carbon dots (CD) and graphene dots) into fluorescent biosensors. ${ }^{25,26}$ Due to their adsorption of DNA with appropriate affinity and the ability to quench different types of fluorophores, graphene-based nanomaterials can act as unique platforms for fluorescence sensing. ${ }^{27}$ Luo et al. demonstrated that different DNA conformations have distinguishable affinities for GO, and this can be used for $\mathrm{pH}$ detection. ${ }^{28}$ Biosensors with novel DNA structures have been developed, along with multi-stranded DNA structures. Triplex DNA is easily formed from a duplex and a third strand via Hoogsteen or reverse Hoogsteen hydrogen base pairing. TA.T and CG.C ${ }^{+}$are two typical Hoogsteen bonds and are commonly utilized for sensor design. Two labelled DNA probes contain a certain amount of TAT under acidic conditions, and the probes fold into triplex DNA structures, which are not absorbed onto the GO surface and so retain strong fluorescence. In contrast, under alkaline conditions the probes contain a single stranded tail, which can be absorbed onto the GO, and so substantially quenching the fluorescence (Fig. 2).

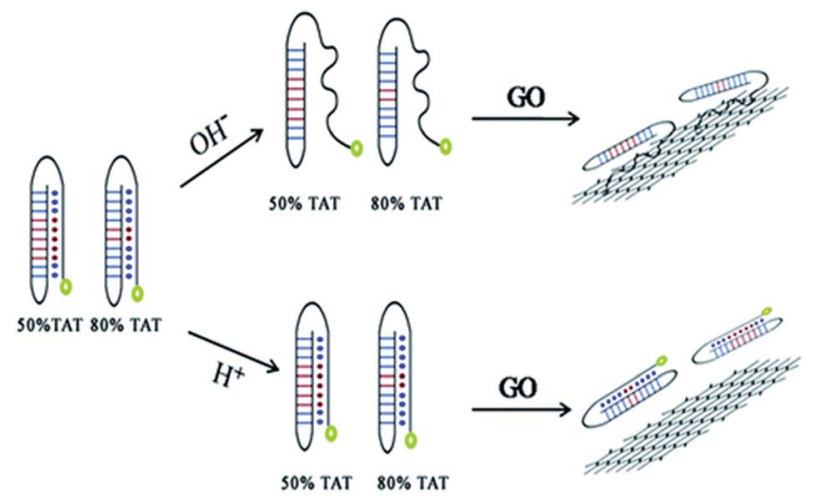

Fig. $2 \mathrm{pH}$ detection by applying the different conformations of a DNA duplex and triplex and their varying affinities to the GO surface. This figure has been adapted from ref. 28, with permission from the Royal Society of Chemistry. 
A sensitive signal readout strategy has made great contribution to the application of DNA biosensors for various targets, including heavy metal ions, toxins, pathogens, as well as in cancer biomarkers. Metal ion detection is a typical application in DNA based biosensors. Many heavy metal ions are harmful when a certain threshold is exceeded, leading to a great risk to human health and to the environment. ${ }^{29-32}$ However, traditional detection methods severely limit the on-site and real-time detections. $^{33,34}$ The interaction between DNA and the metal ions is vital for sensitive sensor design. Based on the conformation transition of the DNA, highly sensitive DNA biosensors have been designed. ${ }^{35,36}$ Furthermore, nanomaterials such as polymers, quantum dots and noble metal nanoclusters, can be modified onto the electrode to improve DNA biosensor performances. Recently, CdSe@CdS quantum dot core-shell nanoparticles were labelled on hemin/G-quadruplex DNA to detect $\mathrm{Pb}^{2+}$. CDs and GO modified DNA fluorescent biosensors were designed for $\mathrm{Hg}^{2+}$ detection by forming a $\mathrm{T}-\mathrm{Hg}^{2+}-\mathrm{T}$ duplex, ${ }^{37,38}$ and $\mathrm{Ag}^{+}$was detected based on a similar mechanism involving $\mathrm{C}-\mathrm{Ag}^{+}-\mathrm{C}$ formation. ${ }^{39}$ There are also artificial bases reported to form stabilized pairs with $\mathrm{Cu}^{2+} \cdot{ }^{\mathbf{4 0 - 4 2}}$ In order to solve the ionic strength dependent problem of DNA-based sensors, $\mathrm{Liu}^{\mathbf{4 3}}$ et al. used 2-aminopurine with high robust fluorescent signalling to label DNA homopolymers for $\mathrm{Hg}^{2+}$ and $\mathrm{Ag}^{+}$detections. To date, $\mathrm{K}^{+},{ }^{44-47} \mathrm{Mg}^{2+}{ }^{48-50} \mathrm{Zn}^{2+},{ }^{51-53} \mathrm{Co}^{2+},{ }^{54} \mathrm{Mn}^{2+}$, ${ }^{4,55}$ and $\mathrm{Cd}^{2+}$ metal-ion dependent DNA biosensors have been obtained through combinatorial selection and rational design of DNA structures, and these biosensors have been applied further in real-time environmental monitoring and for on-site medical diagnostics.

Furthermore, DNA-based biosensors have also been developed for carcinogen and antibiotic detection in food safety. A series of sensitive aptamer-based biosensors were reported to detect aflatoxin B1 (AFB1) using quadruplex DNA on a gold electrode or by cy5-modified DNA probes with electrochemical and fluorescent readouts. ${ }^{56,57}$ Liu et al. ${ }^{58}$ detected microcystinLR via a multiple amplified enzyme-free electrochemical immunosensor, in which $\mathrm{SiO}_{2} @ M S N$-functionalized DNAzyme concatemers load hemin and $\mathrm{MB}$ as a mimic enzyme. In addition, the quantitative detection of streptomycin residues in blood serum, milk and animal derived foods has been reported based on aptamer-complimentary strand conjugates and fluorescence quenching by gold nanoparticles (AuNPs). ${ }^{\mathbf{5 9 , 6 0}}$ Another important antibiotic in food safety and clinical diagnosis, kanamycin, has also been detected by a fluorescent aptasensor based on the catalytic recycling activity of exonuclease and AuNPs. ${ }^{61}$

Most importantly, DNA biosensors have made a great contribution to the early diagnosis and efficient therapy of various diseases. By combining different nanomaterials, such as silver nanoclusters, and gold nanorods, sensitive fluorescence sensors were used for human immunodeficiency virus (HIV) and hepatitis B virus (HBV) detections through the hybridization chain reaction (HCR). ${ }^{\mathbf{6 2 6 3}}$ Different electrochemical/fluorescent DNA sensors have been designed for cancer biomarker detection, involving typical miRNAs, prostate specific antigen (PSA), ${ }^{64}$ and carcinoembryonic antigen (CEA). ${ }^{65}$ For example, ECL biosensors were constructed for cancer relevant DNA/miRNA detection via programmable DNA cyclic amplification. ${ }^{6-68}$ A dual-mode AuNPs@MoS ${ }_{2}$ electrochemical sensor was also constructed for miRNA-21 detection. ${ }^{69}$ In addition, the fluorescent DNA-AgNCs biosensor with a cellspecific internalization aptamer could be internalized into tumor cells specifically, realizing multiple tumor-related miRNA detections and imaging. ${ }^{70}$ The activity of human intracellular telomerase is an important biomarker in primary human tumors for early clinical diagnosis. With high intracellular stability, biocompatibility and good specificity, a silver pyramid probe-based biosensor detecting telomerase activity in situ in living cells has been reported. ${ }^{71}$ A porphyrin-functionalized graphene ECL technique has also been constructed for labelfree ultrasensitive telomerase activity detection, according to the amount of DNA loading on the electrode surface. ${ }^{72}$ Our group has also demonstrated an electrochemically triggered click reaction strategy for an aptamer-based biosensor that effectively detected VEGF $_{165}$, which is another important biomarker in cancer and neuron diseases. ${ }^{73}$

In addition, the non-invasive or minimally-invasive nuclear imaging detections were usually employed to specifically identify diseased tissues at the molecular level, and they play critical roles in biomedical research. ${ }^{74-76}$ For example, fluorescence labelled DNA nanostructures with high biocompatibility and flexibility were designed to perform sentinel lymph node imaging $^{77,78}$ and dual modality targeted imaging detections in cancer cells. ${ }^{79}$ In order to enhance the imaging detection quality, AuNRs were also assembled on the surface of the DNA origami structure, along with an in vivo photothermal therapy function at the same time. ${ }^{80}$

\section{Biomedical therapies using DNA nanotechnology}

Cancer is a leading cause of death worldwide. At present, chemotherapy, ${ }^{\mathbf{8 1 , 8 2}}$ radiotherapy ${ }^{\mathbf{8 3}}$ and immunotherapy are three important therapeutic strategies, but they are also subject to many challenges. Numerous efforts have been made for more effective therapies. In recent years, the emergence of molecular medicine based on DNA nanotechnology has attracted tremendous interest. In this section, the recent research progresses in chemotherapy and immunotherapy involving DNA nanostructures will mainly be summarized.

Chemotherapy as a primary therapy cancer strategy has made great contributions to cancer treatment over the last several decades. However, typical chemotherapy agents exhibit poor drug selectivity and side effects, ${ }^{\mathbf{8 4}}$ therefore it is necessary to develop new chemotherapeutic drug-loading platforms to solve these problems. DNA nanostructures with unique features ${ }^{\mathbf{8 5}-87}$ have been used to design heterogeneous anticancer agents (including molecular drugs, $\mathrm{RNA}^{88}$ and proteins ${ }^{89}$ ) for targeted cancer treatments..$^{\mathbf{9 0}-93}$ A wide range of DNA nanostructures have been used to create chemotherapeutic drugloading platforms, as well as for aptamer-based delivery for the specific uptake of drugs in vivo. ${ }^{94}$ Doxorubicin (DOX) as a typical chemotherapeutic anticancer drug is widely used in 
cancer treatment, as it interacts with DNA and restrains macromolecular biosynthesis. ${ }^{95}$ A DNA icosahedra nanostructure has been used as the nanocarrier of DOX by assembling motifs, demonstrating it as an efficient and specific strategy for epithelial cancer cells. ${ }^{96}$ Furthermore, the release of DOX can be rationally controlled through adjusting the twisting degree of the DNA tubular carrier. With the development of DNA nanotechnology, DNA origami technology has also been created with abundant and complicated nanostructures as drug-loading platforms for DOX (Fig. 3A), showing promising cancer therapeutic efficiency in vivo. ${ }^{97,98}$ For maximum loading of DOX, multiple GC-pair sequences were embedded in a selfdegradable cocoon-like DNA nanoclew (Fig. 3B). ${ }^{99}$ An opencaged pyramidal DNA@DOX nanostructure was developed for drug delivery, which exhibited a significant enhancement in cytotoxicity to breast and liver cancer cells compared to the free DOX. ${ }^{100}$ By combining an aptamer and GC-rich dsDNA, Ma et al. ${ }^{101}$ developed a multifunctional drug delivery platform with high stability, an efficient payload capacity and reduced side effects in order to solve multi-drug resistance through targeted drug delivery. Meanwhile, a novel self-assembled DNA nanostructure was able to specifically recognize cancer cells and further release the loaded anticancer drug at pH 5.0 (Fig. 3C).$^{102}$

With the advantages of a well-defined 3D shape, a uniform size, good biocompatibility and precise spatial addressability, 3D polyhedral structures based on DNA self-assembling promise novel application to in vivo molecular cargo delivery processes. ${ }^{103,104}$ A tetrahedral DNA nanostructure (TDN) is a novel type of 3D DNA nanostructure that has also been rapidly explored in biomedical fields. It was reported that TDN was able to promote cell proliferation. The expression of cyclindependent kinase like-1 gene was up-regulated in the presence of TDN by activating the Wnt/ $\beta$-catenin pathway. ${ }^{105}$ Walsh $^{\mathbf{1 0 6}}$ et al. investigated the access of the DNA tetrahedron cage to cultured mammalian cells without transfection reagent for at least $48 \mathrm{~h}$. Furthermore, it was investigated, utilizing the DNA nanostructure, for effective drug delivery. The endocytic and transport of tetrahedral DNA nanostructures through a caveolin dependent pathway in mammalian cells was demonstrated. Moreover, Krishnan and co-workers ${ }^{\mathbf{1 0 7}}$ employed a novel DNA icosahedron-based intelligent nanovehicle with chemically responsive behaviour for FITC dextran encapsulation and delivery (Fig. 4A). In addition, Gianneschi et al. ${ }^{\mathbf{1 0 8}}$ presented a reversible nanoscale anticoagulant by combining

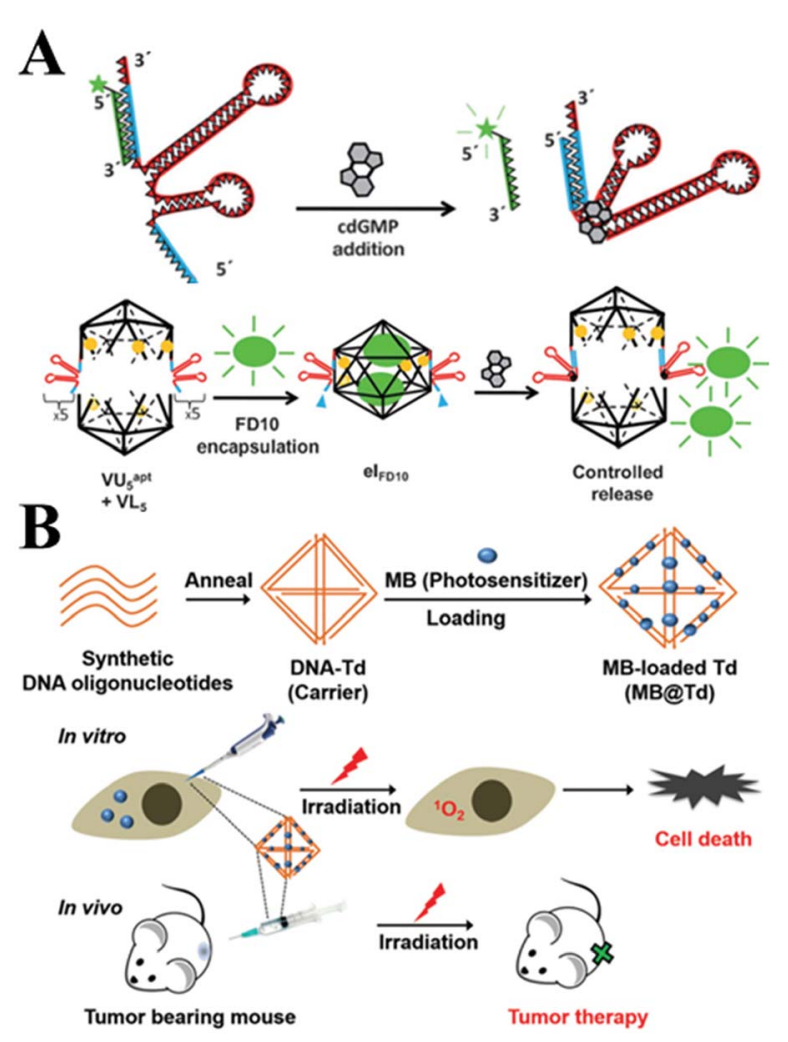

Fig. 4 (A) Controlled release of encapsulated cargo from a DNA icosahedron using a chemical trigger. This figure has been adapted from ref. 107, with permission from John Wiley and Sons. (B) Loading of MB onto DNA Td constructed with four DNA strands for in vivo photodynamic therapy. This figure has been adapted from ref. 109, with permission from the Royal Society of Chemistry.
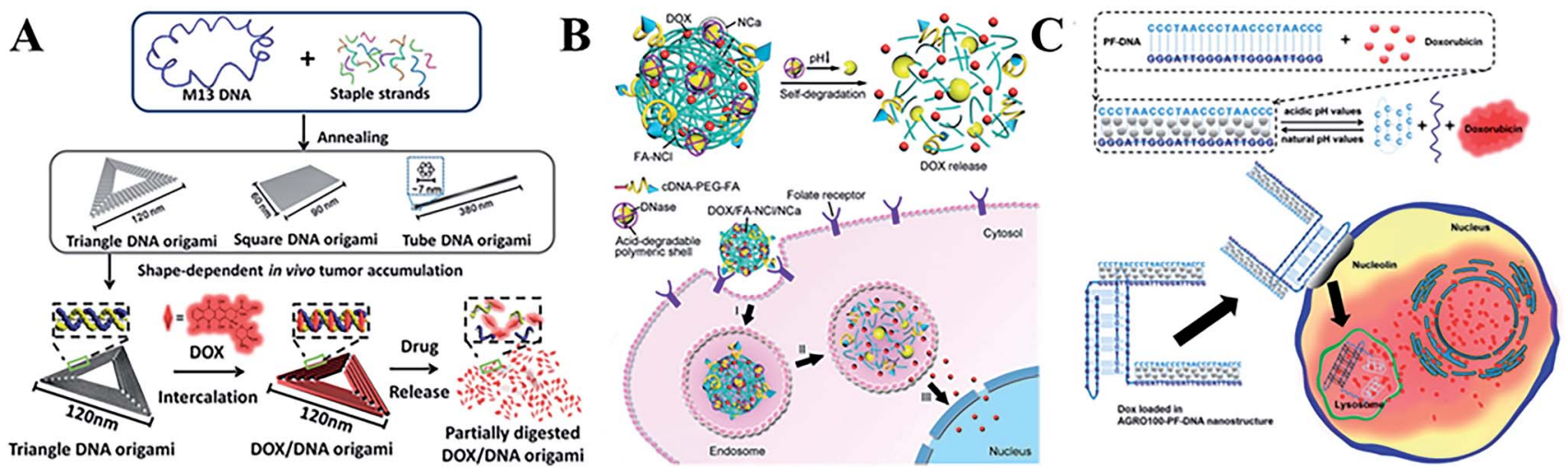

Fig. 3 (A) The triangular, square, and tube DNA origami used as DOX vehicles for cancer therapy. This figure has been adapted from ref. 98, with permission from the American Chemical Society. (B) Cocoon-like self-degradable DNA nanoclew for anticancer drug delivery. This figure has been adapted from ref. 99, with permission from the American Chemical Society. (C) A self-assembled DNA nanostructure for targeted and pHtriggered DOX delivery. This figure has been adapted from ref. 102, with permission from the Royal Society of Chemistry. 
thrombin and DNA-aptamer polymer amphiphilic spherical NPs (DAPA-NPs), which effectively inhibited human plasma clotting. However, this effect can rapidly be reversed by adding the complementary oligonucleotides, in order to control blood circulation times in vivo. In addition, the nano-size DNA tetrahedron carrying $\mathrm{MB}$ provided an effective photodynamic therapy (Fig. 4B). ${ }^{\mathbf{1 0 9}}$

Small interfering RNA is known to interfere with protein synthesis by binding to complementary messenger RNA molecules, which then silences the specific genes being expressed. ${ }^{110-112}$ DNA nanostructures have been enhanced for use as powerful delivery carriers of the therapeutic nucleic agents for cancer targeted therapy. Anderson et al. ${ }^{\mathbf{1 0 3}}$ assembled DNA/siRNA tetrahedral nanoparticles using six ssDNA fragments and six double-stranded siRNAs to deliver siRNA into the target genes. The introduction of nanoparticles improves the stability of tethered RNA molecules, and this greatly enhances their interference efficacy in biomedicine. Recently, it has been reported that DNA nanoparticles (DNPs) with DNA bricks could be easily constructed as delivery vehicles of siRNA, which would target anti-apoptotic protein $\mathrm{Bcl} 2$ and significantly inhibit cell growth in vitro and in vivo. ${ }^{113}$

Moreover, immunotherapy has provided another strategy due to its specificity and minimal side effects compared with chemotherapy. Cytosino-phosphate-guanine (CpG) DNA as a ligand for toll-like receptor 9 (TLR9) has been used for the immunotherapy of cancers, infectious diseases, asthma etc., by triggering the innate immune responses. ${ }^{\mathbf{1 1 4}}$ However, ssDNA containing $\mathrm{CpG}$ sequences is unstable and can be digested in physiological conditions. Much effort has been made to develop CpG DNA nanostructures with high delivery efficiency and low toxicity for clinical applications. ${ }^{92}$ Various complicated DNA nanostructures (TDN, DNA origami and DNA polypod structures etc.) have been fabricated and have significantly enhanced the CpG loading efficiency of the immunostimulatory effect in vivo (Fig. 5A). ${ }^{115,116}$ CpG-tripodna and CpG-hexapodna were also designed to induce a higher tumor necrosis factor alpha (TNF-a) release from RAW 264.7 cells, thus increasing the potency of CpG-SS in vivo. ${ }^{\mathbf{1 1 7}}$ Fan's group ${ }^{\mathbf{1 1 8}}$ has assembled a functional and multivalent DNA tetrahedral nanostructure with unmethylated CpG motifs, and this has enhanced the immunostimulatory effect when entering macrophage-like RAW264.7 cells even without transfection agents. The group has also used a DNA rolling circle amplification (RCA) strategy to assemble DNAorigami, such as nanoribbons, for carrying CpG ODNs. It was demonstrated that this strategy was readily internalized by mammalian cells, and thus enhanced immunostimulatory activity. ${ }^{119}$ Taking advantage of the strong and long-lasting specific antibody response in vivo, the antigen-adjuvant DNA complex has also been demonstrated as a potential candidate to recognize various vaccines. ${ }^{\mathbf{1 2 0}}$ Recently, a DNA vaccine containing a CpG motif was developed, and the cytotoxicity and survival life time were greatly increased. Liu et al. constructed a bicistronic plasmid to extract the fusion genes of survivin/ MUC1 (MS) and IL-2, which showed good effects on colorectal cancer and successfully simplified the whole industrial production process. Furthermore, the anti-tumour effects of this fusion gene could be enhanced by combining it with oxaliplatin. ${ }^{\mathbf{1 2 1}}$ Meanwhile, the dendrimer-like DNA and nanocentipedes structures were considered as efficient vehicles to deliver immunostimulatory $\mathrm{CpG}$ sequences, which could be internalized by cancer cells and trigger the corresponding stronger immune response (Fig. 5B). ${ }^{122,123}$

\section{DNA molecular logic gates and computing}

With the development of technology, the conventional electronic computer based on Boolean logic encounters great technical bottlenecks for complex problems and manufacturing. ${ }^{124}$ However, with the development of DNA nanotechnology, DNA as a basic and promising alternative material for the construction of molecular logic gates has attracted remarkable attention. DNA can perform various logical operations by transforming inputs into defined outputs in logic circuit systems due to its outstanding data-storage capacity, highly specific hybridizations and flexibility in design. ${ }^{125,126}$ Numerous DNA computer applications will be briefly introduced.

A great deal of effort has been devoted to designing and developing typical DNA logic gates, including YES, NOT, AND, NAND, OR, NOR, XOR, XNOR, IMPLY and N-IMPLY etc. The

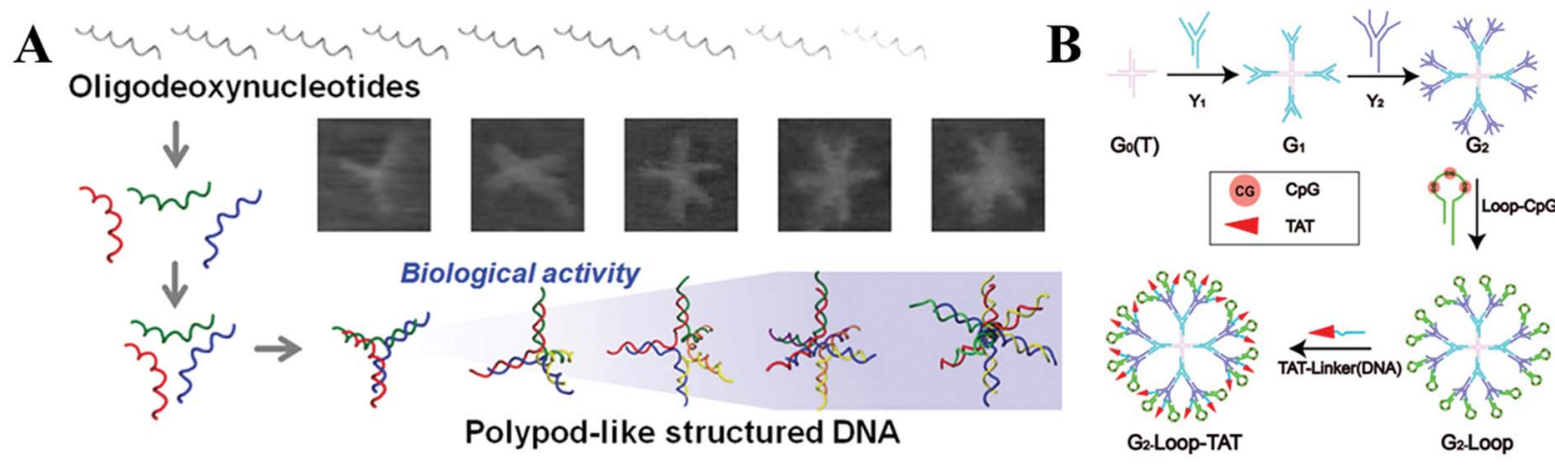

Fig. 5 (A) Nanosized DNA assemblies in polypod-like structures as efficient vehicles for immunostimulatory CpG motifs. (B) A self-assembled DNA dendrimer nanoparticle for efficient delivery of the immunostimulatory CpG motifs. These figures have been adapted from ref. 116 and 122 , with permission from the American Chemical Society. 
inputs of DNA/RNA, metal ions or light will activate the logic gates and then produce output signals based on Watson-Crick base-pairing, DNA strand displacement, DNAzyme cleavage, ${ }^{127}$ nucleic acid ligand binding, ${ }^{128}$ i-motif transformation, DNA hairpins ${ }^{129}$ and PCR. ${ }^{130}$ Ghadiri et al. ${ }^{131}$ successfully created three photonic logic gates, AND, NAND and INHIBIT, using the unique base-pairing properties of DNA and FRET between fluorescent molecules. Subsequently, ssDNA was exploited to invade and displace local sections of complementary dsDNA. A series of entirely AND, OR and XOR logic gates and a half-adder were assembled by AND and XOR gates. ${ }^{132}$

Recently, numerous novel DNA logic gates have been reported. By taking advantage of biocatalysis, colorimetric logic gates and multi-level circuits have been developed based on a typical triplex-helix molecular switch machine and DNAzyme (Fig. 6A), and this paved a simple path for designing complex DNA-based logic devices. ${ }^{\mathbf{1 3 3}}$ Based on the previous work involving DNA interactions with carbon nanotubes, our group has reported novel photoluminescence sperminefunctionalized C-dots for the induction of the DNA B-Z

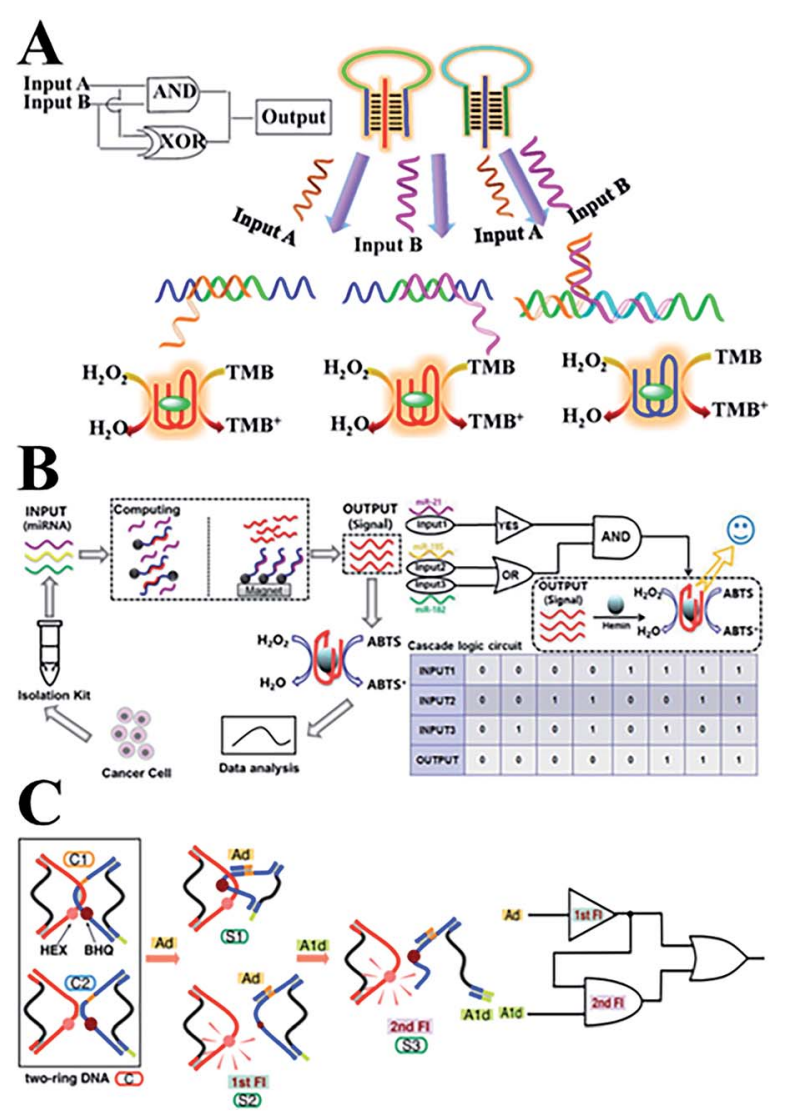

Fig. 6 (A) DNA colorimetric logic gates based on a triplex-helix molecular switch. This figure has been adapted from ref. 133, with permission from the American Chemical Society. (B) An optical DNA logic gate based on strand displacement and magnetic separation, which responds to multiple microRNAs. This figure has been adapted from ref. 136, with permission from Springer Nature. (C) A DNA sequential logic gate using two-ring DNA. This figure has been adapted from ref. 138, with permission from the American Chemical Society. structure transition. Several DNA logic gates under physiological low salt conditions were constructed using a FRET design. ${ }^{134}$ In addition, a multi-level logic gate was built from sequential INHIBIT and AND gates for the analysis of a net XOR gate with an electrochemical signal as the output. In addition, Fan's team ${ }^{\mathbf{1 3 5}}$ constructed a series of on-chip DNA logic gates via DNA strand displacement reactions. By regulating the ssDNA inputs into mammalian cells, the behavior of the cells can be accurately controlled. This has provided an alternative route to programming cell movements and functions in biomedical applications. With the help of hemin-G-quadruplex complexes, a set of optical DNA logic gates and a Boolean logic circuitry were constructed based on strand displacement and magnetic separation. The coloured ABTS product can be formed in response to three microRNA input signals from cancer cells (Fig. 6B). ${ }^{136}$ Moreover, a sequential logic DNA gate was established utilizing a two-ring DNA structure (Fig. 6C), and this recognizes two DNA signals with different triggering sequences via the "loop-open" mechanism. ${ }^{137,138}$

With more sophisticated precision in their uses, DNA molecular logic gates can hold great potential for diagnosis and therapy at the molecular level. In comparison to conventional single input and output states ( 0 or 1 ), DNA-based molecular logic gates usually depend on the change in fluorescent or colorimetric signals to realize multiple detections of small molecules or macromolecules in bioanalysis and biological diagnosis. A series of AND, OR and SET-RESET logic gates have been constructed by employing ion-driven conformational changes of a DNA G-quadruplex. ${ }^{139}$ In addition, an INHIBIT logic gate based on $\mathrm{K}^{+}$or $\mathrm{Pb}^{2+}$-switched DNA structures, a chemical XOR gate and a three-input molecular logic gate was also designed. ${ }^{\mathbf{1 4 0 , 1 4 1}}$ With relentless electronic signals and reusable sensing elements, this device can be applied for continuous monitoring, particularly in heavy metal ion, pathogen, and genetic biomedicine detections. ${ }^{\mathbf{1 4 2}}$ Furthermore, the ECL signals have been used as new outputs using energy or an electron transfer-quenching path. ${ }^{\mathbf{1 4 3}}$ Recently, Macdonald ${ }^{\mathbf{1 4 4}}$ arranged user-friendly deoxyribozyme-based molecular logic gate networks into visual displays, and then further developed a prototype molecular automation. This was able to comprehensively differentiate seven different genotypes of the Lyssavirus genus, and an AND-NOT gate was designed to prevent nonspecific activation. The DNAzyme-DNA complexes have been applied in the design of powerful colorimetric biosensors with logic gate operations to identify DNA, ${ }^{\mathbf{1 4 5}}$ and the target can be viewed directly by colour changes during the OR logic gate operation (Fig. 7A).

Numerous research on the properties and advantages of 3D DNA tetrahedral nanostructures has been reported. ${ }^{\mathbf{1 1 8 , 1 4 6 - 1 4 8}}$ Using a series of reconfigurable DNA tetrahedrons that respond to a target, various scaffold logic gates were constructed. ${ }^{149}$ DNA origami nanostructures also provided programmable platforms for logic gates, which could be operated to capture or release small molecules, proteins, nanoparticles or external light signals. ${ }^{150}$ Kjems and Birkedal demonstrated that the logic gate complexes can control the lid of a 3D DNA origami box with high reliability and high fidelity. ${ }^{151}$ The unique DNA origami 

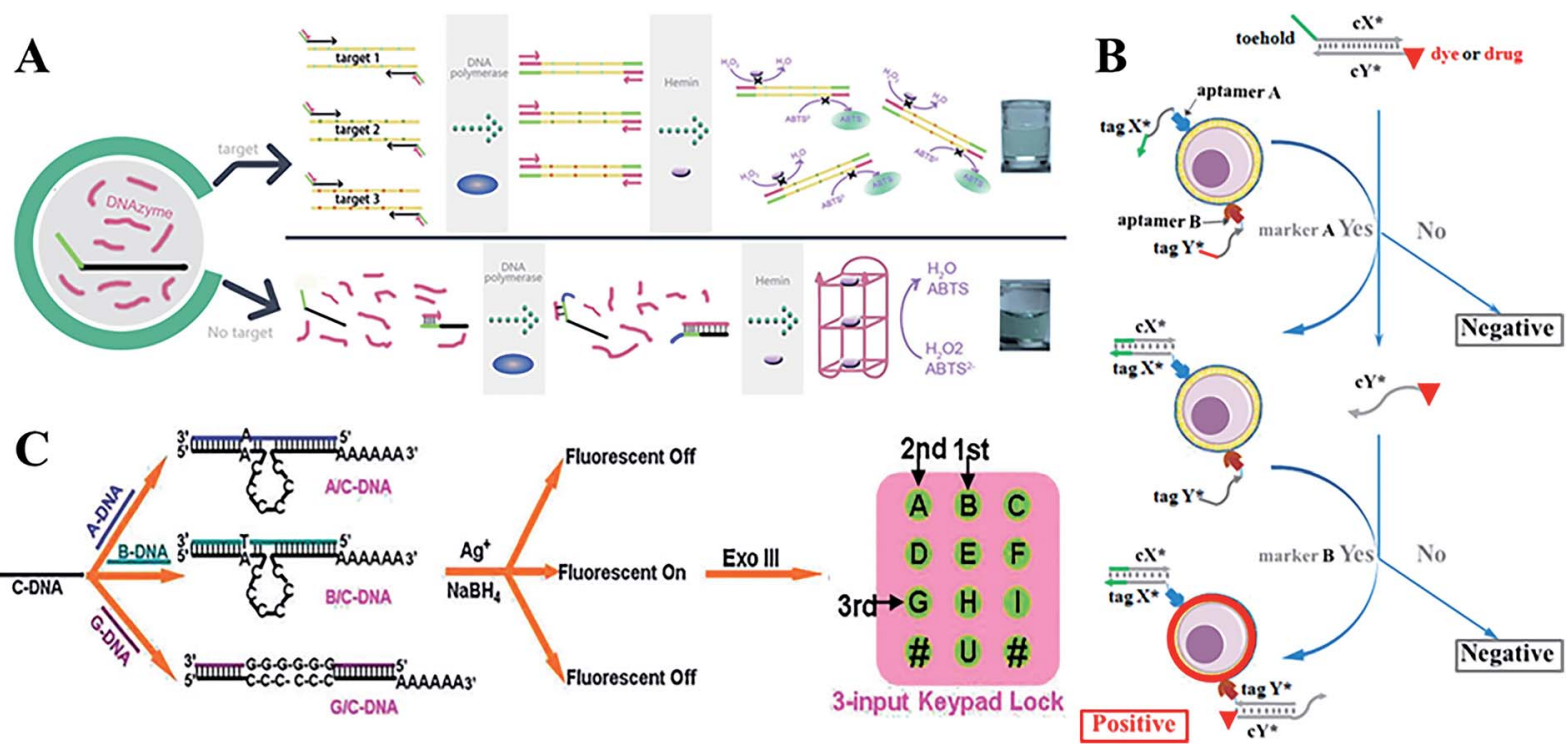

Fig. 7 (A) A colorimetric biosensor based on DNAzyme logic gate operations for DNA screening. This figure has been adapted from ref. 145, with permission from Elsevier. (B) A programmable and multi-parameter DNA-based logic platform for cancer recognition and targeted therapy. This figure has been adapted from ref. 153, with permission from the American Chemical Society. (C) DNA-templated Ag nanoclusters as signal transducers for a resettable keypad lock. This figure has been adapted from ref. 159, with permission from the Royal Society of Chemistry.

structures provide masses of potential applications in nanomedicine for diagnostics and therapeutics. For multiple cancer cell-surface markers, a "Nano-Claw" has been reported to perform autonomous logic analysis. ${ }^{152}$ Meanwhile, by combining the special structure-transition of DNA aptamers with toehold-mediated strand displacement reactions, a diagnostic signal can be produced and targeted photodynamic therapy can be realized. High-order multiple cell-surface markers have been successfully identified via integrating AND, OR and NOT logic gates (Fig. 7B). ${ }^{153}$

Furthermore, researchers have paid much attention to the molecular-scale keypad lock, which is a novel data security device. Its output signals rely on the proper combination of inputs or the inputting sequence. Until now, the fluoresceinlinker-pyrene assembly system and photonic keypad locks using ions as inputs had only been reported. ${ }^{154-156}$ Qu's group first constructed a nucleic acid-based molecular keypad lock with sequence specific recognition of DNA and solid-phase substrates. ${ }^{157}$ Recently, the novel nanomaterial AgNCs as signal transducers that convert inputs into fluorescence output, can be constructed for various DNA-based logic gates and a sequential logic gate. ${ }^{158}$ These AgNC-based logic systems have been used to fabricate a biomolecular resettable keypad for crossword puzzles, which provides a universal design and biocompatible operation. These versatile logic devices with new signal transducer materials are simple in practical applications (Fig. 7C). ${ }^{159}$ Wang et al. further developed a resettable DNAbased keypad lock $^{160}$ and a visible multi-digit DNA keypad lock based on cleavable G-quadruplex DNAzyme and silver microspheres. ${ }^{161}$ Zhou et al. first constructed concatenated logic circuits as a visible keypad-lock security system based on toehold-mediated strand displacement and a three-way DNA junction. This system could reset and cycle for a greater number of times automatically, without an external stimulus, compared to previous reports. ${ }^{162}$

Since 1994, Adleman has used DNA oligonucleotides to perform logical operations for solving complex mathematical problems. ${ }^{163}$ Qian et al. experimentally demonstrated several scaled up digital logic circuits with a four-bit square-root circuit consisting of 130 DNA strands for threshold and catalysis, achieving digital signal restoration within logical operation. ${ }^{164}$ Furthermore, researchers have demonstrated the autonomous smart behaviors of molecular systems using a simple DNA gate architecture for multilayer digital circuits based on the vastness of DNA computing and strand displacement cascades. ${ }^{165}$

\section{DNA molecular machines}

In the design of artificial molecular machines, DNA represents a smart building material with specific base-pairing, predictable assembly, abundant polymorphisms and unique physical/ chemical properties. ${ }^{166}$ By the rational design of a DNA sequence and stimulus conditions, the transformation of DNA structures can be manipulated and can endow DNA with controllable motion or special functions. It is important to study DNA molecular machines during the conversion of energy and the interaction of biomolecules at the nanometer level, as this is important for the development of biosensors, transporters and controlled drug delivery systems. ${ }^{167}$ Over the past few years, the construction of artificial DNA machines has attracted much attention. ${ }^{168,169} \mathrm{~A}$ great deal of machine-like functioning DNA nanostructures have been reported, ${ }^{146}$ such as DNA tweezers, ${ }^{170,171}$ gears, ${ }^{129}$ walkers, ${ }^{172-175}$ cranes,${ }^{176,177}$ catenanes, ${ }^{178}$ rotaxanes, ${ }^{179}$ metronome operations ${ }^{180}$ and so on. ${ }^{181-187}$ For instance, a contractile DNA machine has been developed based on the crosslinking of circular DNA into nanowires, and 
this can be used in target medicine delivery or non-viral gene delivery and will transduce DNA hybridization energy into controlled movement energy on the biomolecular level. ${ }^{188}$ Molecular walking machines have transported cargoes on the nanometer scale in the presence of DNA fuels. ${ }^{189}$ Yuan and Xiang have designed a restriction enzyme-powered, autonomous DNA walking machine to detect sequence-specific target DNA with high sensitivity and selectivity. ${ }^{190}$ Tao et al. ${ }^{191}$ engineered a phage T4 DNA packaging machine by incorporating vaccine/reporter genes, functional enzymes and target ligands to deliver genes and proteins into mammalian cells with a near $100 \%$ efficiency. This has promoted the development of efficacious vaccines against complex HIV-1, malaria and TB infectious agents.

With high sensitivity and selectivity, DNA machines also have astonishing applications in biosensors and screening. ${ }^{192}$ The duplicator-like DNA molecular machines offer a number of DNA templates to fabricate AgNCs for $\mathrm{Hg}^{2+}$ ion detection, ${ }^{193}$ and this autonomous bio-barcode DNA machine has carried out exponential DNA circular amplification for $\mathrm{Hg}^{2+}$, DNA or small biomolecule detection. ${ }^{194}$ Another RCA-based DNA machine has been fabricated by coupling miRNA and a catalytic hairpin for the formation of DNAzyme. ${ }^{195}$ By integrating strand displacement and nicking enzyme signal amplification into a one-step system, polymerase-nicking enzyme synergetic quadratic DNA machines have been designed to sense $\mathrm{Pb}^{2+}$, miRNA and DNA methyltransferase. ${ }^{196,197}$ In addition, powered by the hydrolysis of $\mathrm{NAD}^{+}$, a repair ligation-mediated light-producing DNA machine has been universally developed for DNA, thrombin, adenosine, $\mathrm{K}^{+}$and endonuclease detection in human serum. ${ }^{198}$ Yuan $^{199}$ has constructed an Fc-switched ECL "off-on" sensor for the sensitive detection of cardiac troponin with a DNA walking machine. Willner's group has spent much effort on constructing a set of DNA machines based on the activation of replication and scission reactions or the aggregation of different nanomaterials. ${ }^{200-203}$ In addition, $\mathrm{Hg}^{2+} /$ cysteine as well as $\mathrm{H}^{+} / \mathrm{OH}^{-}$triggers can activate bipedal DNA devices by walking through and stepping on the template track. ${ }^{204,205}$ Depending on the addition of different fuels and anti-fuels, reconfigurable stimuli-responsive DNA machines can be triggered. ${ }^{206,207}$

Very recently, a variety of novel and dynamic DNAhydrogel machines have been constructed. Linked bridge hybridizing was induced to develop split G-quadruplex DNA machines for uracil-DNA glycosylase detection. ${ }^{208}$ The energetic and mechanical performances of compact (fold) and extended (unfold) DNA motifs have been explored, by tethering small DNA hairpins onto the central seam of a DNA origami frame. Yang and $\mathrm{Zhan}^{209}$ have constructed a central axis and an external sliding tube on a DNA origami mechanical device with controllable regulation of the microcosmic structural rigidity of liposome. The used fuel and anti-fuel strands are important for cell proliferation. A novel proton-driven DNA nanopump has also been developed by incorporating a $\mathrm{pH}$-sensitive i-motif structure into a surface-confined 3D DNA tetrahedron (Fig. 8A). ${ }^{210}$ A

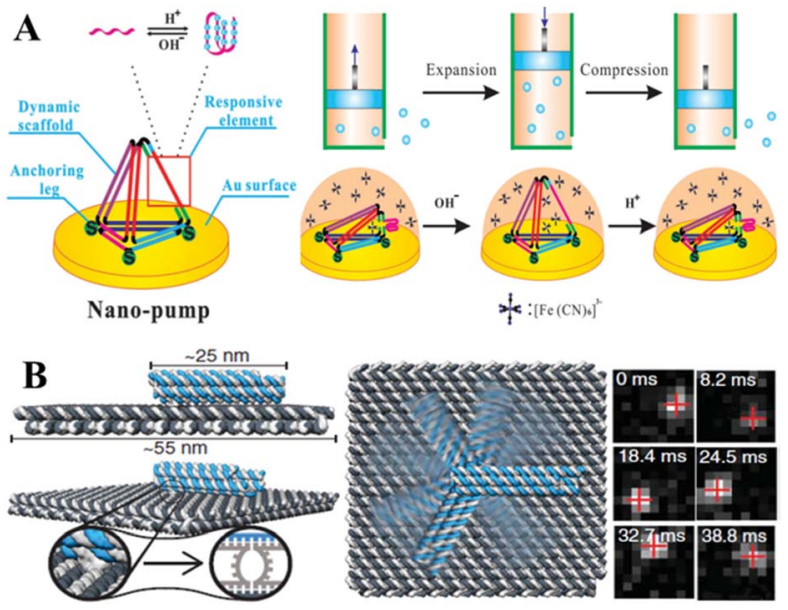

Fig. 8 (A) A surface-confined proton-driven DNA pump using a rigid DNA tetrahedron nanostructure as a dynamic scaffold. This figure has been adapted from ref. 210, with permission from John Wiley and Sons. (B) A molecular platform with an integrated rotatable positioning arm controlled by electric fields. This figure has been adapted from ref. 212, with permission from Science Publishing Group.

plasmonic nanorod decorated with DNA strands has been designed to carry out directional, progressive and reverse walking on a DNA origami, as an efficient walker robot. ${ }^{211}$ Friedrich's group has developed a DNA-based molecular platform with a robotic arm (with a length range from 25 to 400 nanometers) that will be actuated under external electric fields. The robotic arm can rotate in arbitrary positions on the platform within milliseconds, in a precise and computercontrolled way (Fig. 8B). Combined with lithographic patterning and self-assembly techniques, multiple DNA robot arms or extended lattices have been created. The robot arm arrays with defined platform orientation have been applied for electrically driven delivery of molecules or nanoparticles within tens of nanometers. ${ }^{212}$

On the basic research of multi-component DNA origami nanostructures directing folding pathways, ${ }^{213} \mathrm{Su}$ et al. designed a complex 3D DNA origami mechanism to analyse and manufacture DNA machines and robots by assembling basic building blocks together, such as six links or five kinematic joins. ${ }^{214}$ Stimuli-responsive hydrogels as functional matrices can be integrated with DNA hairpin structures, exhibiting switchable mechanical, structural and chemical properties. The DNAhydrogel complex could be used for drug delivery, in valves or actuators, and in biosensors and information process. ${ }^{215} \mathrm{Can}-$ gialosi et al. demonstrated that a 100-fold volumetric expansion was realized by DNA in a hydrogel system upon external stimuli. Then the controllable bend, twist, or actuated shape changes were realized with the successive extension of cross-links with different DNA hairpins. Moreover, the author has further fabricated dynamic DNA "flower" and "crab" hydrogel devices with the petals, antennae, claws, and legs responding to different sequences (Fig. 9). This strategy provided the possibility of building soft DNA robots, programmable devices and smart medicine via diverse biochemical inputs. ${ }^{216}$ 


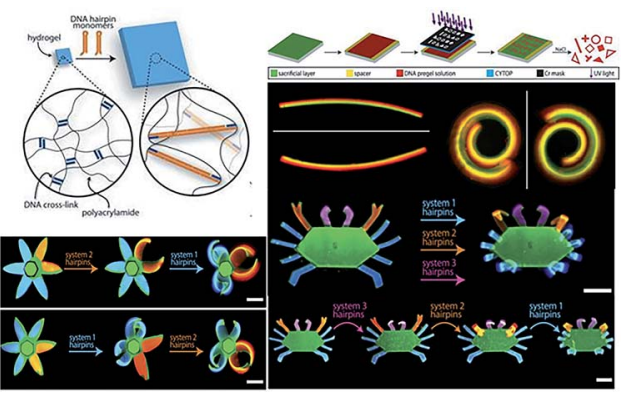

Fig. 9 DNA sequence-directed shape changes of photopatterned hydrogels of six-petal flower and crab structures. This figure has been adapted from ref. 216, with permission from Science Publishing Group.

\section{Conclusions and perspectives}

Over the past decades, much effort has been made towards DNA biomedical applications with the rapid development of DNA nanotechnology. In this mini-review, we have mainly summarized the recent progresses in the design and applications of DNA nanomaterials, including their use in novel biosensors, bioimaging and therapies, DNA logic gates and molecular nanomachines, covering a wide range of aspects of potential future uses of DNA. Notably, despite substantial applications quickly blooming, several issues remain that need to be addressed. One major challenge is that, until now, the developed applications are still highly limited at the bench research stage. Some restrictions are urgently needed to be overcome in order to make a breakthrough, including the difficult construction, unstable and high-cost chemical synthesis, poor reproducibility and being susceptible to interference, especially for the promising clinical applications. In the near future, DNAbased biosensors and biocomputing applications have the potential to be improved by overcoming false interference at the molecular level with a more rigid and stable nanostructure design, or by introducing variable DNA analogues to inhibit degradation in a complex medium. We positively believe that DNA nanomaterials will provide various novel and powerful methodologies in biomedical applications, as well as for exploring new paths to address more complex mathematical logic problems and mechanical behaviours.

\section{Conflicts of interest}

There are no conflicts to declare.

\section{Acknowledgements}

This work was supported by the National Natural Science Foundation of China (NSFC 21705106), the Program for Professor of Special Appointment (Eastern Scholar) at Shanghai Institutions of Higher Learning (No. TP2016023), the Shanghai Sailing Program (17YF1406400) and the Shanghai Natural Science Foundation (No. 18ZR1415400). We also thank Wenxia Liu for the useful discussion.

\section{Notes and references}

1 J. D. Watson and F. H. Crick, Nature, 1953, 171, 964-967.

2 K. Gehring, J. L. Leroy and M. Gueron, Nature, 1993, 363, 561-565.

3 Z. G. Suo, J. Q. Chen, Z. H. Hu, Y. H. Liu, F. F. Xing and L. Y. Feng, Nanofabrication, 2018, 4, 32-52.

4 W. Xu, X. J. Xue, T. H. Li, H. Q. Zeng and X. G. Liu, Angew. Chem., 2010, 48, 6742.

5 L. Y. Feng, C. Q. Zhao, Y. Xiao, L. Wu, J. S. Ren and X. G. Qu, Chem. Commun., 2012, 48, 6900-6902.

6 Y. G. Ke, S. Lindsy, Y. Chang, Y. Liu and H. Yan, Science, 2008, 319, 180-183.

7 Q. Liu, Z. L. Ge, X. H. Mao, G. B. Zhao, X. L. Zuo, J. W. Shen, J. Y. Shi, J. Li, L. H. Wang, X. Q. Chen and C. H. Fan, Angew. Chem., 2018, 57, 7131-7135.

8 L. P. Qiu, H. Zhou, Z. S. Wu, G. L. Shen and R. Q. Yu, New J. Chem., 2014, 38, 4711-4715.

9 T. Kang, S. M. Yoo, I. Yoon, S. Y. Lee and B. Kim, Nano Lett., 2010, 10, 1189-1193.

10 P. Mehrotra, J. Oral. Biol. Craniofac. Res., 2016, 6, 153-159.

11 C. H. Fan, K. W. Plaxco and A. J. Heeger, Proc. Natl. Acad. Sci. U. S. A., 2003, 100, 9134-9137.

12 F. Li, L. M. Yang, M. Q. Chen, Y. Qian and B. Tang, Biosens. Bioelectron., 2013, 41, 903-906.

13 D. Li, S. P. Song and C. H. Fan, Acc. Chem. Res., 2010, 43, 631-641.

14 K. J. Huang, H. L. Shuai and Y. X. Chen, Sens. Actuators, B, 2016, 225, 391-397.

15 Y. P. Wei, X. P. Wei, C. J. Mao, H. L. Niu, J. M. Song and B. K. Jin, Biosens. Bioelectron., 2017, 103, 99-103.

16 N. Arroyo-Curras, K. Scida, K. L. Ploense, T. E. Kippin and K. W. Plaxco, Anal. Chem., 2017, 89, 12185-12186.

17 H. Li, P. Dauphin-Ducharme, N. Arroyo-Curras, C. H. Tran, P. A. Vieira, S. G. Li, C. Shin, J. Somerson, T. E. Kippin and K. W. Plaxco, Angew. Chem., 2017, 56, 7492-7495.

18 H. Li, N. Arroyo-Curras, D. Kang, F. Ricci and K. W. Plaxco, J. Am. Chem. Soc., 2016, 138, 15809-15812.

19 Z. L. Ge, M. H. Lin, P. Wng, H. Pei, J. Yan, J. Y. Sho, Q. Huang, D. N. He, C. H. Fan and X. L. Zuo, Anal. Chem., 2014, 86, 2124-2130.

20 E. A. Hemmig, C. Fitzgerald, C. Maffeo, L. Hecker, S. E. Ochmann, A. Aksimentiev, P. Tinnefeld and U. F. Keyser, Nano Lett., 2018, 8, 1962-1971.

21 J. W. Liu, Z. H. Cao and Y. Lu, Chem. Rev., 2009, 109, 19481998.

22 C. Lu, F. Chen, M. Li, X. D. Guo, S. L. Li, N. Zheng and J. Q. Wang, Food Chem., 2017, 215, 377-382.

23 T. X. Chen, F. Ning, H. S. Liu, K. F. Wu, W. Li and C. B. Ma, Chin. Chem. Lett., 2017, 28, 1380-1384.

24 C. Y. Sun, R. F. Su, J. X. Bie, H. J. Sun, S. N. Qiao, X. Y. Ma, R. Sun and T. H. Zhang, Dyes Pigm., 2017, 149, 867-875.

25 P. Zheng and N. Q. Wu, Chem. - Asian J., 2017, 12, 23432353.

26 Z. B. Liu, B. W. Liu, J. S. Ding and J. W. Liu, Anal. Bioanal. Chem., 2014, 406, 6885-6902. 
27 H. Zhang, H. L. Zhang, A. Aldalbahi, X. L. Zuo, C. H. Fan and X. Q. Mi, Biosens. Bioelectron., 2017, 89, 96-106.

28 F. Y. Luo, Q. Xi, J. H. Jiang and R. Q. Yu, Anal. Methods, 2016, 8, 6982-6985.

29 G. L. Turdean, Int. J. Electrochem., 2011, 139, 343125.

30 C. Gao, X. Y. Yu, S. Q. Xiong, J. H. Liu and X. J. Huang, Anal. Chem., 2013, 85, 2673-2680.

31 K. Tag, K. Riedel, H. J. Bauer, G. Hanke, K. H. R. Baronian and G. Kunze, Sens. Actuators, B, 2007, 122, 403-409.

32 A. Singh, R. K. Sharma, M. Agrawal and F. M. Marshall, Food Chem. Toxicol., 2010, 48, 611-619.

33 Y. Xiang and Y. Lu, Inorg. Chem., 2014, 53, 1925.

34 W. H. Zhou, R. Saran and J. W. Liu, Chem. Rev., 2017, 117, 8272-8325.

35 T. Li, S. J. Dong and E. K. Wang, J. Am. Chem. Soc., 2010, 132, 13156-13157.

36 F. Sun, Z. Y. Wang, Y. Q. Feng, Y. X. Cheng, H. X. Ju and Y. W. Quan, Biosens. Bioelectron., 2017, 100, 28-34.

37 X. Cui, L. Zhu, J. Wu, Y. Hou, P. Y. Wang, Z. N. Wang and M. Yang, Biosens. Bioelectron., 2015, 63, 506-512.

38 A. Ono and H. Togashi, Angew. Chem., 2010, 43, 4300-4302. 39 A. Ono, S. Cao, H. Togashi, M. Tashiro, T. Fujimoto, T. Machinami, S. Oda, Y. Miyake, I. Okamato and Y. Tanaka, Chem. Commun., 2008, 39, 4825-4827.

40 P. Scharf and J. Muller, Chempluschem, 2013, 78, 20-34.

41 N. Megger, J. Johannsen, J. Muller and R. K. O. Sigel, Chem. Biodiversity, 2012, 9, 2050-2063.

42 C. Kaul, M. Müller, M. Wagner, S. Schneider and T. Carell, Nat. Chem., 2011, 3, 794-800.

43 W. H. Zhou, J. S. Ding and J. W. Liu, Biosens. Bioelectron., 2017, 87, 171-177.

44 I. Smirnov and R. H. Shafer, J. Mol. Biol., 2000, 296, 1-5.

45 F. He, Y. L. Tang, S. Wang, Y. L. Li and D. B. Zhu, J. Am. Chem. Soc., 2005, 127, 12343-12346.

46 B. Kim, I. H. Jung, M. Kang, H. K. Shim and H. Y. Woo, J. Am. Chem. Soc., 2012, 134, 3133-3138.

47 H. J. Sun, X. H. Li, Y. C. Li, L. Z. Fan and H. B. Kraatz, Analyst, 2013, 138, 856-862.

48 E. Freisinger and R. K. O. Sigel, Coord. Chem. Rev., 2007, 251, 1834-1851.

49 X. Y. Gao, H. M. Huang, S. Y. Niu, H. Z. Ye, Z. Y. Lin, B. Qiu and G. N. Chen, Anal. Methods, 2012, 4, 947-952.

50 D. Mazumdar, N. Nagraj, H. K. Kim, X. L. Meng, A. K. Brown, Q. Sun, W. Li and Y. Lu, J. Am. Chem. Soc., 2009, 131, 5506-5515.

51 B. Cuenoud and J. W. Szostak, Nature, 1995, 375, 611-614.

52 S. W. Santoro, G. F. Joyce, K. Sakthivel, S. Gramatikova and C. F. Barbas, J. Am. Chem. Soc., 2000, 122, 2433-2439.

$53 \mathrm{~J} . \mathrm{Li}$, W. C. Zheng, A. H. Kwon and Y. Lu, Nucleic Acids Res., 2000, 28, 481-488.

54 K. E. Nelson, H. E. Ihms, D. Mazumdar, P. J. Bruesehoff and Y. Lu, ChemBioChem, 2012, 13, 381-391.

55 M. Chandra, A. Sachdeva and S. K. Silverman, Nat. Chem. Biol., 2009, 5, 718-720.

56 G. Castillo, K. Spinella, A. Poturnayová, M. Šnejdárková, L. Mosiello and T. Hianik, Food Control, 2015, 52, 9-18.
57 W. B. Shim, M. J. Kin, H. Mun and M. G. Kim, Biosens. Bioelectron., 2014, 62, 288-294.

58 C. F. Gan, B. F. Wang, J. Y. Huang, A. Qileng, Z. Y. He, H. T. Lei, W. P. Liu and Y. J. Liu, Biosens. Bioelectron., 2017, 98, 126-133.

59 N. M. Danesh, M. Ramezani, A. S. Emrani, K. Abnous and S. M. Taghdisi, Biosens. Bioelectron., 2015, 75, 123-128.

60 A. S. Emrani, N. M. Danesh, P. Lavaee, M. Ramezani, K. Abnous and S. M. Taghdisi, Food Chem., 2016, 190, 115-121.

61 M. Ramezani, N. M. Danesh, P. Lavaee, K. Abnous and S. M. Taghdisi, Sens. Actuators, B, 2016, 222, 1-7.

62 S. Q. Zhang, K. Wang, K. B. Li, W. Shi, W. P. Jia, X. Y. Chen, T. Sun and D. M. Han, Biosens. Bioelectron., 2017, 91, 374379.

63 X. C. Lu, X. Dong, K. Y. Zhang, X. W. Han, X. Fang and Y. Z. Zhang, Analyst, 2013, 138, 642-650.

64 M. Souada, B. Piro, S. Reisberg, G. Anquetin, V. Noel and M. C. Pham, Biosens. Bioelectron., 2015, 68, 49-54.

65 N. Shahbazi, S. Hosseinkhani and B. Ranjbar, Biosens. Bioelectron., 2017, 253, 794-803.

66 Q. M. Feng, Y. H. Guo, J. J. Xu and H. Y. Chen, ACS Appl. Mater. Interfaces, 2017, 9, 17638-17645.

67 X. N. Yao, Z. H. Guo and X. W. Zheng, Anal. Methods, 2016, 9, 312-321.

68 P. Zhang, Z. Y. Li, H. J. Wang, Y. Zhuo, R. Yuan and Y. Q. Chai, Nanoscale, 2017, 9, 2310-2316.

69 S. Su, W. Cao, W. F. Liu, Z. W. Lu, D. Zhu, J. Chao, L. X. Weng, L. H. Wang, C. H. Fan and L. H. Wang, Biosens. Bioelectron., 2017, 94, 552-559.

70 J. J. Li, J. You, Y. P. Zhuang, C. P. Han, J. F. Hu, A. Wang, K. Xu and J. J. Zhu, Chem. Commun., 2014, 54, 7107-7110.

71 L. G. Xu, S. Zhao, W. Ma, X. L. Wu, S. Li, H. Kuang, L. B. Wang and C. L. Xu, Adv. Funct. Mater., 2016, 26, 1602-1608.

72 L. Wu, J. S. Wang, L. Y. Feng, J. S. Ren, W. L. Wei and X. G. Qu, Adv. Mater., 2012, 24, 2447-2452.

73 L. Y. Feng, Z. Z. Lyu, A. Offenhäusser and D. Mayer, Eng. Life Sci., 2016, 16, 550-559.

74 M. Rudin and R. Weissleder, Nat. Rev. Drug Discovery, 2003, 2, 123-131.

75 J. K. Willmann, N. V. Bruggen, L. M. Dinkelborg and S. S. Gambhir, Nat. Rev. Drug Discovery, 2003, 3, 123-131.

76 T. Hussain and Q. T. Nguyen, Nat. Rev. Drug Discovery, 2008, 7, 591-607.

77 K. R. Kim, Y. D. Lee, T. Lee, B. S. Kim, S. Kim and D. R. Ahn, Biomaterials, 2013, 34, 5226-5235.

78 M. Torabi, S. L. Aquino and M. G. Harisinghani, J. Nucl. Med., 2004, 45, 1509-1518.

79 D. W. Jiang, Y. H. Sun, J. Li, Q. Li, M. Lv, B. Zhu, T. Tian, D. F. Cheng, J. Y. Xia, L. Zhang, L. H. Wang, Q. Huang, J. Y. Shi and C. H. Fan, ACS Appl. Mater. Interfaces, 2016, 8, 4378-4384.

80 Y. Du, Q. Jiang, N. Beziere, L. L. Song, Q. Zhang, D. Peng, C. W. Chi, X. Yang, H. B. Guo, G. Diot, V. Ntziachristos, B. Q. Ding and J. Tian, Adv. Mater., 2016, 28, 10000-10007. 
81 U. Emmenegger and R. S. Kerbel, Nature, 2010, 468, 637638.

82 D. Weycker, H. S. Wu, M. Hagiwara, X. Y. Li and R. L. Barron, Blood, 2014, 124, 2167-2175.

83 D. C. Lombe and B. Jeremic, Clin. Lung Cancer, 2015, 16, 406-412.

84 H. G. Keizer, H. M. Pinedo, G. J. Schuurhuis and H. Joenje, Pharmacol. Ther., 1990, 47, 219-231.

85 P. W. Rothemund, Nature, 2006, 440, 297-302.

86 X. B. Shen, Q. Jiang, J. Y. Wang, L. R. Dai, G. Z. Zuo, Z. G. Wang, W. Q. Chen, W. Jiang and B. Q. Ding, Chem. Commun., 2012, 48, 11301-11303.

87 G. Z. Zhu, J. Zheng, E. Q. Song, M. Donoxan, K. J. Zhang, C. Liu and W. H. Tan, Proc. Natl. Acad. Sci. U. S. A., 2013, 110, 7998-8003.

88 D. R. Han, S. Pal, J. Nangreave, Z. T. Deng, Y. Liu and H. Yan, Science, 2011, 332, 342-346.

89 R. Nunez-Lozano, M. Cano, B. Pimentel and G. da la CuevaMendz, Curr. Opin. Biotechnol., 2015, 35, 135-140.

90 S. Pal, A. T. Deng, H. N. Wang, S. L. Zou, Y. Liu and H. Yan, J. Am. Chem. Soc., 2011, 133, 17606-17609.

91 B. Sacca and C. M. Niemeyer, Chem. Soc. Rev., 2011, 40, 5910-5921.

92 R. Jia, T. Wang, Q. Jiang, Z. G. Wang, C. Song and B. Q. Ding, Chin. J. Chem., 2016, 34, 265-272.

93 Y. L. Wen, L. Y. Li, L. L. Li, L. Xu, W. Liang, S. Z. Ren and G. Liu, Chem. Inform., 2016, 34, 283-290.

94 S. K. Soininen, J. K. Repo, V. Karttunen, S. Auriola, K. H. Vahakangas and M. Ruponen, Toxicol. Lett., 2015, 239, 108-114.

95 M. Chang, C. S. Yang and D. M. Huang, ACS Nano, 2011, 5, 6156-6163.

96 L. H. Tan, K. G. Neoh, E. T. Kang, W. S. Choe and X. D. Su, Macromol. Biosci., 2011, 11, 1331-1335.

97 Q. Jiang, C. Song, J. Nangreave, X. W. Liu, L. Lin, D. L. Qiu, Z. G. Wang, G. Z. Zou, X. J. Liang, H. Yan and B. Q. Ding, J. Am. Chem. Soc., 2012, 134, 13396-13403.

98 Q. Zhang, Q. Jiang, N. Li, L. R. Dai, Q. Liu, L. L. Song, J. Y. Wang, Y. Q. Li, J. Tian, B. Q. Bao and Y. Du, ACS Nano, 2014, 8, 6633-6643.

99 W. J. Sun, T. Y. Jiang, Y. Lu, M. Reiff, R. Mo and Z. Gu, J. Am. Chem. Soc., 2014, 136, 14722-14725.

100 V. Kumar, S. Bayda, M. Hadla, I. Caligiuri, C. Russo Spena, S. Palazzolo, S. Kempter, G. Corona, G. Toffoli and F. Rizzolio, J. Cell. Physiol., 2016, 231, 106-110.

101 J. Liu, T. Wei, J. Zhao, Y. Y. Huang, H. Deng, A. Kumar, C. X. Wang, Z. C. Liang, X. W. Ma and X. J. Liang, Biomaterials, 2016, 91, 44-56.

102 J. Liu, X. W. Ma, C. N. Lei, X. D. Xue, T. Wei, J. Zhao, S. Y. Li and X. J. Liang, J. Mater. Chem., 2016, 4, 3854-3858.

103 H. Lee, A. K. R. Lytton, Y. Chen, K. T. Love, A. I. Park, E. D. Karagiannis, A. Sehgal, Q. Querbes, C. S. Zurenko, M. Jayaraman, C. G. Peng, K. Charisse, A. Borodovsky, M. Manoharan, J. S. Donhoe, J. Truelove, M. Nahrendorf, R. Langer and D. G. Anderson, Nat. Nanotechnol., 2012, 7, 389-393.
104 D. Bhatia, S. Chakraborty and Y. Krishnan, Nat. Nanotechnol., 2012, 7, 344-346.

105 Q. Peng, X. R. Shao, J. Xie, S. R. Shi, X. Q. Wei, T. Zhang, X. X. Cai and Y. F. Lin, ACS Appl. Mater. Interfaces, 2016, 8, 12733-12739.

106 A. S. Walsh, H. F. Yin, C. M. Erben and M. J. A. Wood, ACS Nano, 2011, 5, 5427-5432.

107 A. Banerjee, D. Bhatia, A. Saminathan, S. Chakraborty, S. Kar and Y. Krishnan, Angew. Chem., 2013, 125, 69926995.

108 A. Roloff, A. S. Carlini, C. E. Callmann and N. C. Gianneschi, J. Am. Chem. Soc., 2017, 139, 1644216445.

109 K. R. Kim, D. Bang and D. R. Ahn, Biomater. Sci., 2016, 4, 605-609.

110 E. J. Lee, S. J. Lee, Y. S. Kang, J. H. Ryu, K. C. Kwon, E. Jo, J. Y. Yhee, I. C. Kwon, K. Kim and J. Lee, Adv. Funct. Mater., 2015, 25, 1279-1286.

111 Y. D. Kim, T. E. Park, B. Singh, S. Maharjan, Y. J. Choi, P. H. Choung, R. B. Arote and C. S. Cho, Nanomedicine, 2015, 10, 1165-1188.

112 M. Saraswathy and S. Q. Gong, Mater. Today, 2014, 17, 298306.

113 M. A. Rahman, P. F. Wang, Z. X. Zhao, D. S. Wang, S. Nannapaneni, C. Zhang, Z. J. Chen, C. C. Griffith, S. J. Hurwitz, Z. G. Chen, Y. G. Ke and D. M. Shin, Angew. Chem., Int. Ed., 2017, 56, 16023-16027.

114 K. Mohri, M. Nishikawa, Y. Takahashi and Y. Takakura, Eur. J. Pharm. Sci., 2014, 58, 26-33.

115 V. J. Schuller, S. Heidegger, N. Sandholzer, P. C. Nickels, N. A. Suhartha, S. Endres, C. Bourquin and T. Liedl, ACS Nano, 2011, 5, 9696-9702.

116 K. Mohri, M. Nishikawa, N. Takahashi, T. Shiomi, N. Matsuoka, K. Ogawa, M. Endo, K. Hidaka, H. Sugiyama, Y. Takahashi and Y. Takakura, ACS Nano, 2012, 6, 5931-5940.

117 Y. Takahashi, T. Maezawa, Y. Araie, Y. Takahashi, Y. Takakura and M. Nishikawa, J. Pharm. Sci., 2017, 106, 2457-2462.

118 J. Li, H. Pei, B. Zhu, L. Liang, M. Wei, Y. He, N. Chen, D. Li, Q. Huang and C. H. Fan, ACS Nano, 2011, 5, 8783-8789.

119 X. Y. Ouyang, J. Li, H. J. Liu, B. Zhao, J. Yan, Y. Z. Ma, S. J. Xiao, S. P. Song, Q. Huang, J. Chao and C. H. Fan, Small, 2013, 9, 3082-3087.

120 X. W. Liu, Y. Xu, T. Yu, C. Clifford, Y. Liu, H. Yan and Y. Chang, Nano Lett., 2012, 12, 4254-4259.

121 C. Liu, Y. Xie, B. Sun, F. Geng, F. Zhang, Q. Guo, H. Wu, B. Yu, J. Wu, X. Yu, W. Kong and H. Zhang, Scand. J. Immunol., 2017, 87, 63-72.

122 Y. J. Qu, J. J. Yang, P. F. Zhang, S. L. Liu, K. Zhang, Q. Jiang, C. Li and B. Q. Ding, ACS Appl. Mater. Interfaces, 2017, 9, 20324-20329.

123 W. S. Li, L. Luo, J. Huang, Q. Wang, J. B. Liu, X. Xiao, H. M. Fang, X. H. Yang and K. M. Wang, Chem. Commun., 2017, 53, 5565-5568.

124 V. Balzani, A. Credi and M. Venturi, ChemPhysChem, 2003, 4, 49-59. 
125 Y. Jing, L. J. Shen, J. J. Ma, H. I. Schlaberg, S. Liu, J. Xu and C. Zhang, ACS Appl. Mater. Interfaces, 2013, 5, 5392-5396.

126 T. Carell, Nature, 2011, 469, 45-46.

127 M. N. Stojanovic, T. E. Mitchell and D. Stefanovic, J. Am. Chem. Soc., 2002, 124, 3555-3561.

128 L. Y. Feng, Z. Z. Lyu, A. Offenhausser and D. Mayer, Angew. Chem., 2015, 54, 7693-7697.

129 J. Elbaz, Z. G. Wang, R. Orbach and I. Willner, Nano Lett., 2009, 9, 4510-4514.

130 T. Nojima, T. Yamamoto, H. Kimura and T. Fujii, Chem. Commun., 2008, 32, 3771-3773.

131 A. Saghatelian, N. H. Volcker, K. M. Guckian, V. S. Y. Lin and M. R. Ghadiri, J. Am. Chem. Soc., 2003, 125, 346-347.

132 N. H. Voelcker, K. M. Guckian, A. Saghatelian and M. R. Ghadiri, Small, 2008, 4, 427-431.

133 W. Gao, L. Zhang, Y. M. Zhang, R. P. Liang and J. D. Qiu, J. Phys. Chem. C, 2014, 118, 14410-14417.

134 L. Y. Feng, A. D. Zhao, J. S. Ren and X. G. Qu, Nucleic Acids Res., 2013, 41, 7987-7996.

135 X. M. Qu, S. P. Wang, Z. L. Ge, J. B. Wang, G. B. Yao, J. Li, X. L. Zuo, J. Y. Shi, S. P. Song, L. H. Wang, L. Li, H. Pei and C. H. Fan, J. Am. Chem. Soc., 2017, 139, 10176-10179.

136 X. T. Ji, H. Y. Lv, M. H. Ma, B. L. Lv and C. F. Ding, Microchim. Acta, 2017, 184, 2505-2513.

137 Y. Jing, Z. C. Song, S. Liu, Q. Zhang and C. Zhang, ACS Appl. Mater. Interfaces, 2016, 8, 22451-22456.

138 C. Zhang, L. J. Shen, C. Liang, Y. F. Dong, J. Yang and J. Xu, ACS Appl. Mater. Interfaces, 2016, 8, 9370-9376.

139 M. Moshe, J. Elbaz and I. Willner, Nano Lett., 2009, 9, 11961200.

140 X. L. Feng, X. R. Duan, L. B. Liu, F. D. Feng, S. Wang and D. B. Zhu, Angew. Chem., 2009, 48, 5316-5321.

141 T. Li, E. K. Wang and S. J. Dong, J. Am. Chem. Soc., 2009, 131, 15082-15083.

142 F. Xia, X. L. Zuo, R. Q. Yang, R. J. White, Y. Xiao, D. Kang, X. O. Gong and A. A. Lubin, J. Am. Chem. Soc., 2010, 132, 8557-8559.

143 X. M. Li, L. Sun and T. R. Ding, Biosens. Bioelectron., 2011, 26, 3570-3576.

144 P. Vijayakumar and J. Macdonald, ChemPhysChem, 2017, 18, 1735-1741.

145 C. G. Wang, N. Cheng, L. J. Zhu, Y. C. Xu, K. L. Huang, P. Y. Zhu, S. F. Zhu, W. Fu and W. T. Xu, Anal. Chim. Acta, 2017, 987, 111-117.

146 R. P. Goodman, I. A. T. Schaap, C. F. Tardin, C. M. Erben, R. M. Berry, C. F. Schmidt and A. J. Turberfield, Science, 2005, 310, 1661-1665.

147 R. P. Goodman, R. M. Berry and A. J. Turberfield, Chem. Commun., 2004, 12, 1372-1373.

148 A. S. Walsh, H. F. Yin, C. M. Erben, M. J. A. Wood and A. J. Turberfield, ACS Nano, 2011, 5, 5427-5432.

149 H. Pei, L. Liang, G. B. Yao, J. Li, Q. Huang and C. H. Fan, Angew. Chem., 2012, 51, 9020-9024.

150 F. R. Li, H. R. Chen, J. Pan, T. G. Cha, I. L. Medintz and J. H. Choi, Chem. Commun., 2016, 52, 8369-8372.

151 R. M. Zadegan, M. D. E. Jepsen, L. L. Hildebrandt, V. Birkedal and J. Kjems, Small, 2015, 11, 1811-1817.
152 M. X. You, L. Peng, N. Shao, L. Q. Zhang, L. P. Qiu, C. Cui and W. H. Tan, J. Am. Chem. Soc., 2014, 136, 1256-1259.

153 M. X. You, G. Z. Zhu, T. Chen, M. J. Donovan and W. H. Tan, J. Am. Chem. Soc., 2015, 137, 667-674.

154 D. Margulies, C. E. Felder, G. Melman and A. Shanzer, J. Am. Chem. Soc., 2007, 129, 347-354.

155 M. Suresh, A. Ghosh and A. Das, Chem. Commun., 2008, 3906-3908.

156 J. Andreasson, S. D. Straight, T. A. Moore, A. L. Moore and D. Gust, Chemistry, 2009, 15, 3936-3939.

157 F. Pu, Z. Liu, X. J. Yang, J. S. Ren and X. G. Qu, Chem. Commun., 2011, 47, 6024-6026.

158 Z. Z. Huang, Y. Tao, F. Pu, J. S. Ren and X. G. Qu, Chem. Eur. J., 2012, 18, 6663-6669.

159 Z. X. Zhou, Y. Q. Liu and S. J. Dong, Chem. Commun., 2013, 49, 3107-3109.

160 W. Hong, Y. Du, T. S. Wang, J. Y. Liu, Y. Q. Liu, J. Wang and E. K. Wang, Chemistry, 2012, 18, 14939-14942.

161 J. B. Zhu, X. Yang, L. B. Zhang, L. L. Zhang, B. H. Lou, S. J. Dong and E. K. Wang, Chem. Commun., 2013, 49, 5459-5461.

162 J. H. Chen, S. G. Zhou and J. L. Wen, Angew. Chem., 2015, 54, 446-450.

163 L. M. Adleman, Science, 1994, 266, 1021-1024.

164 L. Qian and E. Winfree, Science, 2011, 332, 1196-1201.

165 L. Qian, E. Winfree and J. Bruck, Nature, 2011, 475, 368372.

166 C. Teller and I. Willner, Curr. Opin. Biotechnol., 2010, 21, 376-391.

167 C. H. Lu, B. Willner and I. Willner, ACS Nano, 2013, 7, 83208332.

168 M. K. Beissenhirtz and I. Willner, Org. Biomol. Chem., 2006, 4, 3392-3401.

169 J. M. Abendroth, O. S. Bushuyev, P. S. Weiss and C. J. Barrett, ACS Nano, 2015, 9, 7746-7768.

170 I. Willner and V. Allen, Org. Biomol. Chem., 2006, 4, 33813382.

171 R. Chhabra, J. Sharma, Y. Liu and H. Yan, Nano Lett., 2006, 6, 978-983.

172 Y. Tian and C. Mao, J. Am. Chem. Soc., 2004, 126, 1141011411.

173 W. B. Sherman and N. C. Seeman, Nano Lett., 2004, 4, 12031207.

174 T. Omabegho, R. Sha and N. C. Seeman, Science, 2009, 324, 67-71.

175 J. S. Shin and N. A. Pierce, J. Am. Chem. Soc., 2004, 126, 10834-10835.

176 Y. Tian, Y. He, Y. Chen, P. Yin and C. D. Mao, Angew. Chem., Int. Ed., 2005, 44, 4355-4358.

177 S. K. Kufer, E. M. Puchner and H. E. Gaub, Science, 2008, 319, 594-596.

178 Z. G. Wang, J. Elbaz and I. Willner, Angew. Chem., Int. Ed., 2012, 51, 4322-4326.

179 J. Elbaz, Z. G. Wang, F. A. Wang and I. Willner, Angew. Chem., Int. Ed., 2012, 51, 2349-2353. 
180 D. Ackermann, T. L. Schmidt, J. S. Hannam, C. S. Purohit, A. Heckel and M. Famulok, Nat. Nanotechnol., 2010, 5, 436-442.

181 C. Buranachai, S. A. Mckinney and T. Ha, Nano Lett., 2006, 6, 496-500.

182 D. Lubrich, J. Lin and J. Yan, Angew. Chem., 2008, 47, 70267028.

183 J. Bath, S. J. Green and A. J. Turberfield, Angew. Chem., 2005, 117, 4432-4435.

184 S. Sahu, T. H. Labean and J. H. Reif, Nano Lett., 2008, 8, 3870-3878.

185 H. Zhang and N. C. Seeman, Nano Lett., 2006, 6, 2899-2903.

186 Y. Chen, M. S. Wang and C. D. Mao, Angew. Chem., 2004, 43, 3554-3557.

187 S. Modi, M. G. Swetha, D. Goswami, G. D. Gupta, S. Mayor and Y. Krishnan, Nat. Nanotechnol., 2009, 4, 325-330.

188 K. Lund, A. J. Manzo, N. Dabby, N. Michelotti, A. JohnsonBuck, J. Nangreave, S. Taylor, R. J. Pei, M. N. Stojanovic, N. G. Walter, E. Winfree and H. Yan, Nature, 2010, 465, 206-210.

189 N. F. Wang, P. Y. Fu, J. Song and H. F. Li, Asian J. Chem., 2013, 25, 6666-6668.

190 Y. Chen, Y. Xiang, R. Yuan and Y. Q. Chai, Nanoscale, 2015, 7, 981-986.

191 T. Pan, M. Mahalingam, B. S. Marasa, Z. H. Zhang, A. K. Chopra and V. B. Rao, Proc. Natl. Acad. Sci. U. S. A., 2013, 110, 5846-5851.

192 H. L. Li, J. T. Ren, Y. Q. Liu and E. K. Wang, Chem. Commun., 2014, 50, 704-706.

193 J. J. Yin, X. X. He, X. K. Jia, K. M. Wang and F. Z. Xu, Analyst, 2013, 138, 2350-2356.

194 J. Wan, X. L. Ma and L. Xing, Sens. Actuators, B, 2013, 178, 615-620.

195 J. Y. Zhuang, W. Q. Lai, G. N. Chen and D. P. Tang, Chem. Commun., 2014, 50, 2935-2938.

196 Y. Zhao, F. Chen, Q. Zhang, Y. Zhao, X. L. Zuo and C. H. Fan, NPG Asia Mater., 2014, 6, e131.

197 Q. Zhang, F. Chen, F. Xu, Y. X. Zhao and C. H. Fan, Anal. Chem., 2014, 86, 8098-8105.

198 Q. Xu, Y. Zhang and C. Y. Zhang, Chem. Commun., 2015, 51, 5652-5655.
199 Z. Q. Xu, Y. W. Dong, J. Y. Li and R. Yuan, Chem. Commun., 2015, 51, 14369-14372.

200 D. Li, A. Wieckowska and I. Willner, Angew. Chem., Int. Ed., 2008, 47, 3927-3931.

201 M. K. Beissenhirtz, R. Elnathan, Y. Weizmann and I. Willner, Small, 2007, 3, 375-379.

202 B. Shlyahovsky, D. Li, Y. Weizmann, R. Nowarski, M. Kotler and I. Willner, J. Am. Chem. Soc., 2007, 129, 3814-3815.

203 Y. Weizmann, Z. Cheglakov and I. Willner, J. Am. Chem. Soc., 2008, 130, 17224-17225.

204 Z. Wang, J. Elbaz and I. Willner, Nano Lett., 2011, 11, 304309.

205 X. Q. Liu, A. Niazov-Elkan, F. A. Wang and I. Willner, Nano Lett., 2013, 13, 219-225.

206 X. Q. Liu, C. H. Lu and I. Willner, Acc. Chem. Res., 2014, 47, 1673-1680.

207 X. J. Qi, C. H. Lu, X. Q. Liu, S. Shimron, H. H. Yang and I. Willner, Nano Lett., 2013, 13, 4920-4924.

208 E. C. Schoeneweiss and B. Sacca, Nanoscale, 2017, 9, 44864496.

209 N. Wan, Z. P. Hong, H. D. Wang, X. Fu, Z. Y. Zhang, C. Li, H. Xia, Y. Fang, M. T. Li, Y. Zhan and X. L. Yang, Small, 2017, 13, 1700866-1700869.

210 D. Zhu, H. Pei, G. B. Yao, L. H. Wang, S. Su, J. Chao, L. H. Wang, A. Aldalbahi, S. P. Song, J. Y. Shi, J. Hu, C. H. Fan and X. L. Zuo, Adv. Mater., 2016, 28, 6860-6865.

211 C. Zhou, X. Duan and N. Liu, Nat. Commun., 2015, 6, 81028106.

212 E. Kopperger, J. List, S. Madhira, F. Rothfischer, D. C. Lamb and F. C. Simmel, Science, 2018, 359, 296-301.

213 A. E. Marras, L. Zhou, V. Kolliopoulos, H. J. Su and C. E. Castro, New J. Phys., 2016, 18, 055005-055009.

214 H. J. Su, C. E. Castro, A. E. Marras and L. F. Zhou, J. Mech. Des., 2017, 139, 1590-1599.

215 J. S. Kahn, Y. Hu and I. Willner, Acc. Chem. Res., 2017, 50, 680-690.

216 A. Cangialosi, C. Yoon, J. Liu, Q. Huang, J. K. Guo, T. D. Nguyen, D. H. Gracias and R. Schulman, Science, 2017, 357, 1126-1129. 